rev.relac.int.estrateg.segur.11(2):239-270,2016

\title{
LA APLICACIÓN DE LAS TECNOLOGÍAS DE INFORMACIÓN Y COMUNICACIÓN EN LA PREVENCIÓN COMUNITARIA DEL DELITO: LOS CASOS DE GEORREFERENCIACIÓN EN MONTERREY, MÉXICO*
}

\author{
Jorge Francisco Aguirre Sala**
}

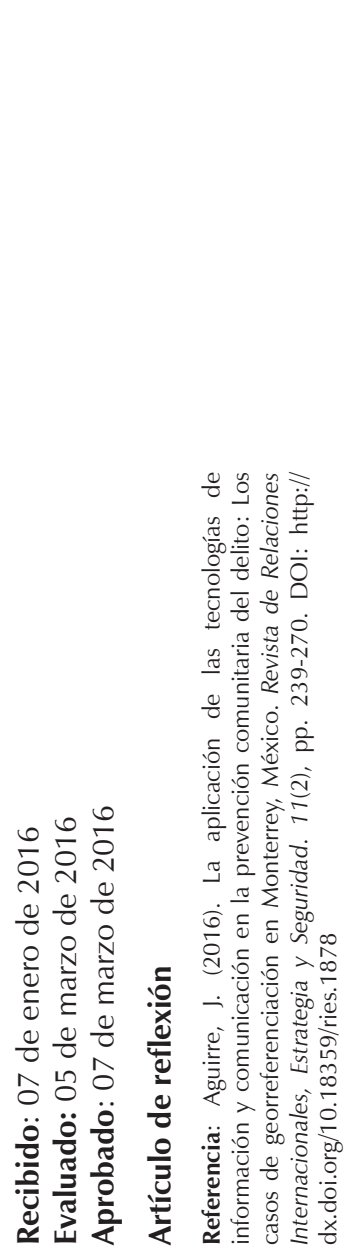

\section{RESUMEN}

El objetivo es mostrar los apoyos de Internet en la prevención comunitaria del delito. El marco teórico general establece que la teoría de la prevención comunitaria constituye una síntesis de la prevención situacional y ambiental. Además, por tratarse de un asunto comunitario, es necesario añadir la concepción de gobernanza. El apoyo de Internet se focaliza en la construcción comunitaria de la georreferenciación delictiva. El marco referencial en este estudio es la Estrategia Nacional Digital mexicana que visualiza la prevención con auxilio de las redes sociales electrónicas. El método y el estudio de caso es el análisis cualitativo del uso de Internet en el área urbana de Monterrey, Nuevo León, México. La muestra toma los tres únicos ejemplos que inicialmente se desarrollan para dicha área.

\footnotetext{
Investigación financiada por los organismos colaboradores: Instituto de Investigaciones Sociales, Universidad Autónoma de Nuevo León y Escuela de Investigaciones en Seguridad Pública.

** Doctor en filosofía con especialidades posdoctorales en Psicología terapéutica y comunitaria. Colabora en la Escuela de Investigaciones en Seguridad Pública de la Universidad de Ciencias de la Seguridad del Estado de Nuevo León, México. Adscrito al Instituto de Investigaciones Sociales de la Universidad Autónoma de Nuevo León. Correo electrónico: jorge.aguirres@uanl.mx
} 
Las variables de mayor importancia son las tipologías de alertas delictivas y la validación de su información electrónica. Como resultado se obtienen algunas evaluaciones y recomendaciones. También se hacen algunas reflexiones sobre el papel reactivo o de proximidad que la Policía en el Estado de Nuevo León podría ejercer, sobre la base comparativa de la Policía Nacional colombiana, la Policía de Carabineros de Chile y la Policía Nacional Civil de El Salvador.

Palabras clave: gobernanza, Internet, prevención delictiva, transversalidad.

\title{
THE APPLICATION OF INFORMATION AND COMMUNICATION TECHNOLOGIES IN COMMUNITY CRIME PREVENTION: THE CASES OF GEOREFERENCING IN MONTERREY, MEXICO
}

\begin{abstract}
The aim is to present the support of the Internet in community crime prevention. The general theoretical framework establishes that the theory of community prevention is a summary of situational and environmental prevention. In addition, because it is a community issue, it is necessary to add the concept of governance. Internet support focuses on community building in criminal georeferencing. The reference framework in this study is the Mexican National Digital Strategy displaying prevention with the help of electronic social networks. The method and the case study is the qualitative analysis of Internet use in the urban area of Monterrey, Nuevo Leon, Mexico. The sample takes only three examples that were initially developed for the area. The most important variables are the types of criminal alerts and validation of electronic information. As a result some assessments and recommendations are obtained. Some reflections on the reactive role or proximity police in the state of Nuevo León could exert on the comparative basis of the Colombian National Police, the Carabineros Police and the National Civil Police of El Salvador are also made.
\end{abstract}

Key words: Governance, Internet, Crime Prevention, Transversality

\section{A APLICAÇÃO DE TECNOLOGIAS DE INFORMAÇÃO E COMUNICAÇÃO NA COMUNIDADE PREVENÇÃO DO CRIME: OS CASOS DO GEO- REFERENCIAMENTO EM MONTERREY, MÉXICO}

\section{RESUMO}

O objetivo é mostrar o apoio da Internet na prevenção da comunidade no crime. O quadro teórico geral afirma que a teoria da prevenção comunitária é um 
resumo da prevenção situacional e ambiental. Além do mais, por se tratar de um problema de comunidade, é necessário adicionar o conceito da governabilidade. Suporte Internet centra-se na construção da comunidade em matéria penal georeferenciamento. O quadro referencial neste estudo é a Estratégia Nacional Digital mexicana, que ver, nas redes sociais eletrônicas a ajuda preventiva. O método e o estudo de caso é a análise qualitativa do uso da Internet na área urbana de Monterrey, Nuevo León, México. A exposição apresenta apenas três exemplos que inicialmente foram desenvolvidos para esta área. As variáveis de maior importância são de tipologia de alertas para os delitos e a validação de sua informação eletrônica. Como resultado são obtidos algumas avaliações e recomendações. Se faz também algumas reflexões sobre o papel da reação ou da proximidade da policia no Estado de Nuevo León poderia exercer sobre a base de comparação com a Policia Nacional da Colômbia, a Policia Carabineros e da Policia Nacional Civil de El Salvador.

Palavras-chave: Governarão, Internet, prevenção da criminalidade, transversalidade.

Vencí a los zetas por facebook, Jaime Rodríguez ("El Bronco")

\section{Introducción}

El 25 de noviembre de 2013 el Gobierno de la República Mexicana dio a conocer la Estrategia Digital Nacional, nombrándola también "México Digital". Su propósito principal era aprovechar el potencial de las Tecnologías de la Información y Comunicación (TIC) como elemento catalizador del desarrollo del país. La estrategia contiene cinco objetivos, el quinto de ellos es la Seguridad Ciudadana.

La noción de Seguridad Ciudadana es concebida por el Gobierno de la República Mexicana (2013) en el sentido de: "Utilizar a las TIC para prevenir la violencia social, articulando los esfuerzos de la ciudadanía y de las autoridades en torno a objetivos comunes para promover la seguridad, y también para prevenir y mitigar los daños causados por desastres naturales" (p. 15). Si se ahonda en el sentido de esta declaración, se notará que destacan los aspectos de la prevención del delito y de la gobernanza en lo concerniente a la convergencia de esfuerzos ante propósitos compartidos.

A lo anterior se añaden varios objetivos secundarios. En los primeros tres de los cuatro objetivos secundarios, 
en materia del marco estructural de la Estrategia Digital Nacional, se expresa más explícitamente la idea de prevención del delito digitalizada, pues el Gobierno de la República (2013) afirma:

Generar herramientas y aplicaciones de denuncia ciudadana en múltiples plataformas; desarrollar instrumentos digitales para la prevención social de la violencia; impulsar la innovación cívica por medio de las TIC, y prevenir y mitigar los daños causados por desastres naturales mediante el uso de las TIC (p. 18).

La aplicación de los soportes tecnológicos, obviamente, resulta imprescindible para la digitalización; el énfasis se pone ahora en la prevención del delito, en la gobernanza como estrategia para la prevención y en la escala de la transversalidad.

En ese tenor, el presente texto apunta a mostrar los aportes y posibilidades de la Internet en la prevención del delito, después de exponer el marco teórico de la prevención comunitaria vinculada con la gobernanza. Dichos aportes y posibilidades se analizan cualitativamente, y además se trata de recabar algunos proyectos significativos en el caso de la Ciudad de Monterrey, Nuevo León, México. Al mismo tiempo se pretende resolver preguntas teóricas como: ¿qué es la prevención del delito comunitaria y qué condiciones exige para ser transversal?, ¿qué aportes contiene la evolución de Internet para la prevención comunitaria del delito?, y otras preguntas de índole más práctica como: ¿cuáles son las fortalezas y las áreas de oportunidad para Nuevo León? Como cuestión corolaria, ¿Fuerza Civil (la Policía estatal de Nuevo León) debe ampliar su margen de acción hacia la prevención y la proximidad con el apoyo de las redes sociales cibernéticas y las plataformas electrónicas en franca integración con la gobernanza?

\section{Marco teórico}

La criminología contemporánea considera la prevención del delito en tres categorías: social, situacional y ambiental (Palacios, 2014a). Categorías que tienen algunos aspectos específicos y peculiares que no comparten entre sí, pero a su vez poseen otros que le son comunes, equivalentes y altamente vinculados. De entre los aspectos comunes, los tres tipos de prevención coinciden en los niveles estructurales de intervención. Estos son descritos por Núñez (2011):

La prevención primaria tiene su base en la educación y va dirigida a todas las personas; [...] la prevención secundaria va dirigida a atacar factores de riesgo presentes en determinados grupos de personas [...] así como en zonas de alta criminalidad. La prevención terciaria se conduce hacia la población reclusa a través del trabajo y la educación (programas de readaptación) (p. 69). 
Además de los niveles estructurales de intervención, otro factor en común es la disuasión. De esos elementos y todo lo que hay detrás de estos surge un común denominador que, a su vez, permite generar una síntesis de las prevenciones social, situacional y ambiental en un modelo comprensivo: la prevención del delito de manera comunitaria.

La prevención comunitaria del delito puede definirse, de acuerdo con Sozzo (2000) como: "técnicas de intervención que están orientadas a la comunidad/vecindario" (p. 37), y siguiendo a Pavarini (1994) puede especificarse con la siguiente paráfrasis: la prevención comunitaria busca reconstruir el control social del territorio por parte de quien lo habita.

La reconstrucción del control implica la participación de los habitantes de un territorio y también de la fuerza pública, por ende, la prevención comunitaria involucra en sus proyectos a los ciudadanos y al Estado. De ahí la necesidad de la gobernanza local y transversal para vincular a estas instancias, como se mostrará en la siguiente sección. Por lo pronto puede apuntarse que la gobernanza constituye una idea que se ha desarrollado desde distintas perspectivas, incluso algunas de estas son ambiguas y contradictorias por los intereses soterrados de algunas instancias del sector privado ante la apertura de visión y misión manifiesta por el sector público. No obstante, en términos generales puede concederse, siguiendo a Cerrillo (2005) que:

La gobernanza está constituida por las normas y reglas que pautan la interacción en el marco de redes de actores públicos, privados y sociales interdependientes en la definición del interés general en entornos complejos y dinámicos. La gobernanza se asocia a una mayor implicación de actores no gubernamentales en el diseño e implementación de las políticas públicas $y$, al fin y al cabo, en la definición del interés general (p. 9).

Los objetivos secundarios específicos para la Seguridad Ciudadana (más allá de los objetivos secundarios del marco estructural señalados antes) de la Estrategia Digital Nacional evidencian la necesidad de la gobernanza para llevar a cabo la prevención comunitaria del delito. Entre dichos objetivos específicos se encuentran:

Desarrollar herramientas digitales de
difusión de información oportuna
para la prevención social de la
violencia [...] Proveer información
por medios digitales que permita a
los ciudadanos desarrollar acciones
preventivas para no ser víctimas
de violencia [...] Potenciar la
innovación cívica y la capacidad
de la ciudadanía para participar
en los asuntos públicos en materia
de seguridad [...y en términos
generales] Incentivar la co-creación
con la ciudadanía, de nuevos
servicios públicos y de soluciones
a problemas públicos, a través de
herramientas digitales (Gobierno de
la República, 2013, p. 25).

Desarrollar herramientas digitales de difusión de información oportuna para la prevención social de la violencia [...] Proveer información por medios digitales que permita a los ciudadanos desarrollar acciones preventivas para no ser víctimas de violencia $[\ldots]$ Potenciar la innovación civica y la capacidad de la ciudadanía para participar en los asuntos públicos en materia de seguridad [...y en términos generales] Incentivar la co-creación con la ciudadanía, de nuevos servicios públicos y de soluciones a problemas públicos, a través de la República, 2013, p. 25). 
En cada uno de estos propósitos las acciones de participación ciudadana desempeñan un papel central para auxiliar al Estado a cumplir con su misión en materia de seguridad. Sin participación ciudadana, el Estado de Derecho degeneraría en un Estado fallido. Por tanto, la Estrategia Digital Nacional reitera las bondades de la gobernanza.

En términos específicos, los elementos de la gobernanza, para resolver las cuestiones públicas en la escala comunitaria, son: la búsqueda de mayor simetría entre los ciudadanos $y$ el Estado, el consenso como medio y evidencia de esa mayor simetría, las fórmulas cooperativas, la delegación de acciones estatales en iniciativas privadas y el abordaje de los problemas (sobre todo los de seguridad, cohesión social y calidad de vida) en soluciones transversales. La transversalidad es un aporte enorme de la gobernanza, porque muchas de las jurisdicciones departamentales de la gestión pública están limitadas a realizar solo las acciones facultadas que les compete según la ley. Es decir, el Estado de Derecho limita al proceder del gobierno, mientras que la participación ciudadana puede ampliar las competencias de este.

Desde lo anterior se conjetura que, en el inventario de elementos particulares de la gobernanza -que apuntan a los programas de prevención comunitaria y garantizan la transversalidad-, se encuentran los siguientes: 1) la participación de actores públicos y privados (empresas, organizaciones no gubernamentales, asociaciones no lucrativas, entidades que agrupan a profesionales, etcétera) para definir las políticas públicas y estrategias de acción (por ejemplo en la creación y operación de Consejos Ciudadanos de Seguridad), 2) la acción en red, es decir, un sistema sociocibernético -tomando este término en su sentido etimológico- (por ejemplo la constitución de Comisarias vecinales o barriales, las instancias de mediación de conflictos, la vinculación entre policía comunitaria y los vecindarios vigilantes), 3) la prestación de algunos servicios públicos por instancias privadas (la autorización de servicios de seguridad privada), 4) la actualización y apertura de bases de datos electrónicas ante las demandas de la sociedad digital que exigen mayor eficacia, eficiencia y transparencia en las tareas de seguridad.

El último elemento, como se ha expuesto, está explícito en los objetivos secundarios del marco estructural y en los objetivos secundarios específicos en materia de Seguridad Ciudadana de la Estrategia Nacional Digital (Gobierno de la República, 2013, pp. 18 y 25). Además, según la propia Estrategia Digital Nacional, impactan al Plan Nacional de Desarrollo 20132018 en varias metas, entre otras la denominada "México en Paz", donde en concreto se pretende: "Desplegar canales de comunicación que permitan a la ciudadanía participar en 
la garantía de la seguridad nacional" (Gobierno de la República, 2013, p. 34). En consecuencia, la prevención comunitaria del delito, si bien se concibe en una primera escala local, alcanza a coadyuvar los aspectos nacionales de seguridad, y ello solo es posible cubriendo los requerimientos de información que la ciudadanía puede aportar al Estado.

Al precisar las áreas de incidencia de la prevención comunitaria deben enumerarse: a) la relación de la ciudadanía con las instituciones policiales; b) el fortalecimiento de lazos sociales intracomunitarios, y c) el gobierno local, este último "debido a su directa relación con la población, así como al conocimiento detallado del territorio" (Dammert, 2005, p. 134). Estos aspectos, vuelven a constatar la necesidad de la información que desde la comunidad se debe aportar al Estado, y sobre todo la adecuada concepción de la gobernanza para no limitarla al sesgo que pudiera darle solo el gobierno. De ahí la justificación del siguiente apartado que la expone desde sus principales teóricos.

\section{Prevención comunitaria y gobernanza}

Las Tecnologías de la Información y la Comunicación han evolucionado a los medios de participación ciudadana y también las formas de administración y gestión gubernamental. Ello da pauta a la distinción entre democracia electrónica y gobierno electrónico
(Aguirre, 2015). Pero considerando la modalidad de la gobernanza resulta innecesario matizar dicha distinción porque se vincula a la gobernanza. No obstante la prevención comunitaria del delito, en razón de su transversalidad y su anclaje en la gobernanza, requiere de la convergencia entre los sectores ciudadanos y los gubernamentales, es decir, constituye un punto de intersección entre el gobierno electrónico y la democracia electrónica.

La convergencia entre los sectores ciudadanos y los gubernamentales se da propiamente en la gobernanza. La gobernanza es el espacio social donde la participación ciudadana no se proyecta en reclamos ante el Estado, sino, por el contrario, se transforma en interacción con el Estado. Por tanto, es una instrumentación del poder ciudadano en el gobierno.

La noción de gobernanza promueve un sano equilibrio entre el Estado y la sociedad civil. A pesar de los vínculos con los poderes de facto, como el mercado neoliberal que la hacen vulnerable a los intereses de grupos hegemónicos, la gobernanza apunta a un nuevo gobierno que abandona el férreo control monopólico por parte del Estado. Por tanto, no sigue al pie de la letra la jerarquía de las escalas gubernamentales, sino que opera en interacción de redes autónomas con estructuras y procesos de información, enlace y codecisión. 
En consecuencia, la gobernanza posee mayor capital social y capacidad de participación ciudadana que la mera gobernabilidad. Busca nivelar la asimetría de poder que los partidos políticos autoritarios cooptaron al convertirse en bloques herméticos y cuya misión se redujo a la eficacia de la contienda electoral. Ello les conllevó un alejamiento de las capacidades ciudadanas en el ámbito local, vínculo que es necesario para resolver las cuestiones públicas en la escala comunitaria, aplicar soluciones desde los intereses y recursos de ciudadanos particulares y disolver conflictos concretos a través del consenso.

Otras distinciones entre la gobernabilidad y la gobernanza se deducen a partir del ensayo de Paniagua, Borunda y Camargo (2012) y la compilación de los 10 textos de referencia fundacional que realizó Cerrillo (2005). Mientras que en la gobernabilidad se impone la institucionalización estatal que mediatiza o coloniza la participación ciudadana, en la gobernanza la participación ciudadana en asuntos públicos es directa y la intermediación del Estado se da en fórmulas cooperativas donde se hacen presentes nuevas formas de regulación que requieren negociación y coordinación. En la gobernabilidad se instaura la verticalidad estatal, aún en los procedimientos, ponderaciones y agendas de las consultas ciudadanas, mientras que en la gobernanza se procura la horizontalidad democrática a través de los consensos deliberativos que no están sujetos a estratos jerarquizados. En la gobernabilidad también se observa que el Estado asigna las condiciones que deberán poseer las redes ciudadanas (a través de los reglamentos que constituyen la estructura y función de los Consejos Ciudadanos), en contraste con la gobernanza las redes sociales poseen mayor simetría entre los ciudadanos y el Estado. También en la gobernabilidad el Estado tiene la prerrogativa exclusiva para tomar acciones y definir políticas públicas; en contraste, la gobernanza procura la cooperación y hasta la delegación de acciones estatales. La realización del bien común y de los intereses generales no se encuentra en el monopolio del Estado y se ubica en la interacción del poder público, la iniciativa privada y la participación ciudadana. Prats (2005) acota que:

La Comisión Europea, en la preparación de su Libro Blanco sobre la Gobernanza de 2001, adoptó la visión de que el modelo de gobernanza por redes se adaptaba mejor que los modelos jerárquicos tradicionales al contexto socioeconómico actual, caracterizado por los cambios rápidos, la fragmentación y problemas de políticas interconectados y complejos (p. 162).

Y ello se debió a que las recientes versiones de la gestión pública resultaron insuficientes en muchos países. Los departamentos ejecutivos o agencias del gobierno no pudieron abarcar monopólicamente el cono- 
cimiento de especialidad para enfrentar los problemas y porque los desafíos, sobre todo los de seguridad, requieren soluciones transversales. Las jurisdicciones departamentales de la gestión pública están limitadas entre sí por las múltiples facultades que a cada una jurídicamente le compete.

Así, pues, la gobernanza nace de la necesidad de crear estructuras y procesos de interacción entre las instancias ciudadanas afectadas y el Estado para adoptar responsabilidades comunes y diferenciadas al constituir una forma de decidir con pluralidad de actores en tendencias de mayor horizontalidad y equilibrio. Por tanto, la gobernanza, particularmente aplicada a la seguridad ciudadana y la prevención del delito, debe ejercerse con los principios democráticos de transparencia, participación, subsidiariedad horizontal, complementariedad y proporcionalidad entre actores públicos y privados.

Las fórmulas iniciales de gobernanza; autogobierno, cogobierno y gobierno jerárquico que Kooiman (2005) había propuesto, e inspiraron a muchos teóricos, quedan rebasadas por la participación ciudadana. Significativamente esto acontece en el caso de elevar el nivel de vida por medio de la prevención del delito, que busca la minimización de un gobierno formal y la maximización de los objetivos compartidos nacidos de una soberanía sustentada más allá de la autoridad del Estado como única instancia para ejercer la fuerza pública. Es decir, la prevención comunitaria del delito encarna la metáfora de Osborne y Gaebler (1992) más el dirigir que el remar, que distingue muy bien la gobernanza de la gobernabilidad (sobre todo del poder ejecutivo), y la participación de la ciudadanía de la mera obediencia ciega a la autoridad encargada de velar por el orden público y la paz social (llámese Policía, Ejército, Marina o Armada).

La noción de gobernanza, no obstante, recibe una crítica que también interpela a la prevención comunitaria del delito. Ambas -gobernanza y prevención comunitaria- enfatizan los procedimientos y/o la deliberación y descuidan la eficacia de los resultados (Peters y Jon, 2005, pp. 123 y ss). Además, se alega que:

[...] el desempeño mejora cuando las decisiones se focalizan en los productos y resultados más que en los insumos y procedimientos -y que además- la gobernanza no es un sustituto del gobierno, sino una modalidad de gobernación con el gobierno [...] que replantea sus roles, formas organizativas y procedimentales (Prats, 2005, pp. 152, 171).

Y aún más severamente Aguilar (2007) critica:

Las evidencias disponibles conducen más bien a sostener la hipótesis de que la gobernanza 
nueva tiene su factor causal crucial en el enlace entre el proceso gerencial y el proceso político-civil que ha caracterizado a las reformas institucionales [...] El retorno a la gobernanza por el gobierno [...] es una opción tal vez imaginable pero no viable (p. 11).

Ante estas críticas la gobernanza requiere consolidarse de manera efectiva y eficaz. $Y$ por obedecer también a los intereses básicos del bien común, se propone una versión específica: la modalidad de la prevención comunitaria del delito con base en la participación ciudadana.

En este sentido, un acercamiento a precisar la prevención del delito lo ofrece Van Dijk: “[...] todas las políticas, medidas y técnicas, fuera de los límites del sistema de justicia penal, dirigidas a la reducción de las diversas clases de daños producidos por actos definidos como delitos por el Estado" (1990, p. 205). A partir de este concepto pueden precisarse diversas formas de prevención. En primer lugar, las políticas, medidas y técnicas referidas en la definición del Van Dijk derivan en tácticas situacionales, ambientales, sociales y comunitarias. Las dos primeras apuntan a la reducción de oportunidades para la realización de los actos que, según los códigos penales, tipificarían como delitos. Ambas tienen un doble enfoque: la atención puede dirigirse a evitar que haya agentes del delito y/o apuntar a quienes pudieran ser pacientes (víctimas) del delito. En el primer enfoque las acciones se dirigen hacia la disuasión encaminada a los potenciales victimizadores y la reinserción social para los victimarios. En el segundo enfoque se halla la prevención del delito en manos de la posible víctima, prevención que no logra rebasar la táctica situacional y/o ambiental. La prevención situacional se alcanza al implementar obstáculos mecánicos y/o electrónicos para disuadiral delincuente bajo las premisas de la teoría de la elección racional, es decir, bajo la fórmula costo/beneficio o riesgo/éxito implicadas en la labor de delinquir. La prevención ambiental se logra en la media en que las realidades arquitectónicas y urbanísticas reducen las oportunidades del delito en función al control de acceso, la vigilancia y el refuerzo territorial (Hernando, 2008).

De mayor dificultad son los retos de la prevención social, pues considera que el crimen es causado por las desigualdades sociales $y$, en consecuencia, las soluciones estriban en que existan mejores salarios, menores tasas de desempleo, mayor educación y, en general, condiciones de alta, o al menos satisfactoria, calidad de vida tanto en lo individual, lo familiar y lo colectivo. Quizá el primero en postular este tipo de prevención fue Alexandre Lacassagne (1843-1924) para quien, en palabras de Núñez (2011): "el delito no era consecuencia de un atavismo en el hombre [como lo había propuesto Ferri, Garófalo y Lombroso] sino que atribuye al medio social un papel importante en la aparición de conductas criminales" 
(p. 60). Ideas similares y ampliadas, que según Núñez (2011) también pueden encontrarse en las propuestas criminológicas de Robert K. Merton, Glueck y Edwin H Sutherland. Sin duda alguna, el enfoque de la prevención social del delito guarda razón: muchos delitos se evitarían al fortalecer los lazos familiares de los infractores, haber tenido el privilegio de la educación por unos buenos padres que ejercieron la vigilancia adecuada, haber asistido a una escuela con disciplina humanitaria y atenta a evitar la deserción, y sobre todo, si se cuenta con un medio social que ofrece buenas oportunidades laborales y opciones sanas para el goce del tiempo libre.

Social, situacional o ambiental, la prevención del delito en una comunidad involucra a la ciudadanía y las esferas del sector público. Entre los sectores de la ciudadanía que participan en estas tareas se encuentran las asociaciones, como las organizaciones no gubernamentales, las instituciones de asistencia privada, los frentes y escuelas de seguridad ciudadanos, las redes de apoyo y solidaridad, las asociaciones juveniles y de adultos mayores, las instancias cívicas de mediación vecinales o de trabajo social entre pandillas barriales, las asociaciones de colonos, los grupos de colonos y, por supuesto, los ciudadanos individuales no organizados que tienen afinidad o se afilian a los programas de gobernanza. Además, también destacan las redes de apoyo y comunicaciones, tanto por los medios masivos de comunicación convencionales como por las redes sociales electrónicas.

El sector público involucra principalmente a las policías. Los tribunales, ministerios públicos de justicia o juzgados, jueces y legisladores, si bien tienen papeles importantes en la prevención del delito, más oportunamente se aplican a la persecución, juicio y rehabilitación de los infractores. En lo concerniente a los cuerpos policiales, por lo general, en la mayoría de los países están estructurados en tres escalas: la Policía nacional o de orden federal, la Policía de escala estatal y la local o municipal.

El sistema policial se divide en estas tres escalas en razón simétrica a los niveles de violencia o delito que atienden (Palacios, 2013). Por ello mismo se diferencian los niveles de capacitación y presupuestos o asignación de recursos. La existencia de las tres escalas conlleva a discusiones teóricas sobre los beneficios de un mando único, de una sola Policía nacional capacitada en tres niveles y del propósito de adiestramiento y adoctrinamiento que oscila entre la reacción y la prevención. El caso del nivel estatal, precisamente por los éxitos que ha tenido en Nuevo León, México, la corporación de Fuerza Civil, se discute en los corolarios que suceden a las conclusiones de este texto. En general se considera que la violencia extrema, que consiste en el ataque a policías, labores de aprehensión 
de miembros del crimen organizado y operaciones especiales contra el terrorismo o acciones que vulneran la soberanía nacional, corresponde ser atendida por la Policía nacional o federal porque posee mayor número de elementos, armamento, equipo técnico y fuerza de reacción. Además, porque estos delitos y otros similares obedecen al grupo de delitos del fuero federal. Mientras que los delitos del fuero común corresponden a la violencia media que radica en robo de vehículos, extorsiones, delitos sexuales, homicidios y secuestros, y corresponde ser atendida por la Policía de nivel estatal porque los infractores requieren reacciones desde el parámetro medio a alto con la necesidad de menor número de elementos $y$, por tanto, menor armamento y equipo técnico. La violencia baja se distingue también por delitos del fuero común, que por lo general afectan la integridad de las personas y su patrimonio, como por ejemplo, los casos de robo a transeúnte, robos a casa de habitación o automóvil en ausencia de habitantes y conductores, robos a comercios y bancos, violencia familiar y lesiones no letales, y todo ello corresponde atenderse por la Policía local o municipal y que, precisamente por la naturaleza de sus menores riesgos o efectos, cabe en la prevención comunitaria que se ejerce en conjunto por la ciudadanía y la Policía.

La acción clave en la prevención comunitaria del delito -acción que se ejecuta con las aportaciones o insumos de la ciudadanía y de la Policía-, es la disuasión. La disuasión puede lograrse en simetría contra las tres condiciones del delito, es decir, contra el motivo, los medios y la oportunidad. Si un posible infractor posee motivos, medios y oportunidades para delinquir, entonces solo le resta calcular el riesgo sobre el probable beneficio de su acción. Una disuasión completa evitará los motivos, los medios y las oportunidades del delito. En general, evitar los motivos del delito es tarea exclusiva de la prevención social. Contrarrestar los medios del delito es tarea de la prevención situacional, y evitar las oportunidades del delito es tarea de la prevención ambiental. Pero la disuasión requiere, además, atacar a priori las causas mezcladas del delito (por ejemplo, la deserción escolar que provoca la vagancia en parques abandonados y de ahí el contacto con delincuentes que iniciarán en la carrera criminal a personas inocentes). Para atender el común denominador de las prevenciones y las causas y eslabones entremezclados del delito está la síntesis de los tres tipos de prevenciones representada en la prevención comunitaria, precisamente, cuando tiene el papel de controlar un territorio por sus habitantes.

La disuasión se logra con patrullaje, presencia ciudadana proactiva en muchos sentidos positivos, mecanismos físicos (bardas, rejas en ventanas, cerraduras sofisticadas) y mecanismos electrónicos (alarmas de movimiento, detectores de armas o códigos de 
barras, cámaras, puertas de seguridad, etcétera). Pero ya sea a través del patrullaje, de la participación ciudadana o la aplicación de mecanismos ad hoc, la información de dónde, cuándo y cómo aplicar los instrumentos de disuasión preventiva es sustancial. Esa información debe ser viral, o al menos tener dirección bilateral entre comunidad yautoridades policiales. Así, por ejemplo, si existen robos en serie a casa de habitación con un mismo modus operandi, entonces esa serie seguramente está en proceso por una misma banda criminal y las autoridades policiales deberían contar con las denuncias correspondientes, información que proviene de la ciudadanía y que las autoridades pueden sistematizar (por georreferenciación espacial, temporal, por los modos operandi -forzar cerraduras o romper ventanas-y estilos -hurto de joyas y electrodomésticos o solo objetos de valor fácilmente transportables, etcétera-) y, a su vez, esa misma información, ya sistematizada y completada, debe proporcionarse a la comunidad.

El patrullaje es la actividad que principalmente desea la ciudadanía para incrementar su percepción de seguridad. Sin embargo, para que el patrullaje sea eficiente y eficaz debe contar con estrategias que minimicen sus costos y maximicen sus resultados. Para ello la actividad preventiva debe organizarse a través de la cartografía policial. Es decir, el patrullaje debe ser proactivo y no reactivo, lo cual significa conocer muy bien el territorio sobre el cual se desea recuperar o mantener el control. Para ello es necesario establecer en las cartografías de la prevención las variables del delito y constantes del territorio.

Las constantes de un territorio son: sus límites, la ubicación de puestos de salud, colegios y escuelas, de sedes universitarias, iglesias, hospitales, supermercados, bares, discotecas, billares, estación de trenes y autobuses, farmacias, casas de cambio y bancos, cajeros automáticos, hoteles y estacionamientos, puentes, parques y oficinas privadas y públicas $y$, en general, la clasificación preponderante del tipo de territorio: habitacional, industrial, comercial, educativo, etcétera. En términos policiales, los territorios se dividen en zonas, sectores y cuadrantes, estos últimos también son denominados polígonos. La Policía debe conocer ese cúmulo de información para realizar los itinerarios y estrategias de sus patrullajes.

Las variables en el territorio son los tipos de delitos e incidentes que ocurren en diferentes tiempos y ubicaciones. Es decir, la organización de la información debe darse según el lugar, días y horarios y tipos de crímenes. Por ejemplo, puede suponerse que será más común el asalto a transeúntes cercanos a los cajeros automáticos los días en que se paga a empleados que en otras fechas; o que los delitos sexuales se cometerán en las cercanías y rutas hacia las fábricas o escuelas 
en horarios previos o posteriores a las horas de mayor movilización.

Las variables y constantes se interrelacionan y provocan el diseño de actividades ciudadanas y policiales de manera táctica. Por ende, esa información debe recabarse y sistematizarse lo más completa posible. Con ello se alcanza un logro muy importante: la sistematización informativa, desde la escala de zonas hasta la de cuadrantes. Autoridades y ciudadanos no conseguirían esto sin la aplicación transversal de las TIC.

Las autoridades policiales, en el sentido de recabar la información, dependen de la ciudadanía. Y la ciudadanía, en el sentido de recibir la información complementada, sistematizada y programada para efectuar las tácticas de prevención, depende de las disposiciones del Estado. De ahí que las TIC en la prevención del delito, como instrumentos, y la gobernanza, como modelo de actuación, aporten uno de los vínculos más estratégicos para el desarrollo de programas preventivos.

\section{Prevención comunitaria y tecnologías de información y comunicación}

Las TIC evolucionan rápidamente y son muy dúctiles y líquidas. Ello provoca la sensación de poco dominio sobre estas y la desconfianza de su veracidad para ejercer el control. Para concebir correctamente su utilidad ha de iniciarse por establecer la diferencia entre una red social cibernética y una plataforma electrónica en Internet; así se aprovecharán al máximo los aportes de la evolución de Internet enfocados a la prevención comunitaria del delito.

Son muchas más las diferencias entre plataformas electrónicas y redes sociales cibernéticas de las que suelen imaginarse. En las primeras se encuentran: el correo electrónico, los wikis (en especial Wiki-leaks y la Wiki-pedia no solo en el sentido de quién las consulta, sino también de quiénes las construyen). Las segundas se constituyen por los chats, foros, blogs; el Facebook, el Twitter, las cuentas de YouTube de colaboración abierta, las cuentas de Mp3, y el P2P (Peer to peer, o red de pares que se constituye sin clientes ni servidores) y paralelamente a estos se encuentran las redes comerciales, como Flickr, Tuenti, Myspace, etcétera, los recientes Instagram y Periscope deben incluirse en la lista de las redes sociales. Las plataformas y las redes sociales no poseen las mismas funciones para los efectos de la participación ciudadana y la gobernanza, pero siempre pueden construir comunidades que se solidarizan y protegen entre sí.

Se trate de una plataforma electrónica o de una red social cibernética, toda esta tecnología ha de enfocarse a diversos tipos de incidencia digital ejercidos por la participación ciudadana en la gobernanza. A diferencia de los medios tradicionales (radio y televisión) y la versión web 1.0, los usuarios pueden 
ser a la vez receptores y emisores; eso es vital para vincular autoridades policiales y ciudadanos participativos del control territorial o para estructurar comisarías ciudadanas.

Internet carece de barreras de ingreso, toda vez que se posee acceso técnico; puede propagarse en "tiempo real" $y$ por tanto es útil para advertir y prevenir. Adolece de compromisos clientelares porque cada usuario a la vez es un protagonista y un receptor. Además, las aplicaciones de Internet de la web 2.0 y 3.0 se comportan con independencia de la cantidad de receptores y cada usuario incrementa exponencialmente su valor. Ello debe usarse como criterio para validar la información ciudadana respecto a la actividad delictiva, pues cualquiera que lo desee puede "subir" un Twitt, video o un post y establecer conversaciones en línea, enviar mensajes instantáneos, transmitir por telefonía o tener acceso remoto a otros dispositivos, y en consecuencia, mentir. Para evitar esta desventaja puede adoptarse la metodología de verificación triangular, como ocurren en las Ciencias Sociales, al verificar por otras fuentes la coincidencia o discrepancia de la información. El sistema Likter de ciudadanos registrados y con la posibilidad de "subir" fotos de un mismo evento es un intento de validar la información.

En contraste a la posible desventaja anterior, Internet enriquece a la ciudadanía con la inclusión de identidades diferenciadas o minorías que, de otro modo, siempre quedarían en la marginación. Ello es importantísimo para las víctimas del delito, pues pueden recibir apoyo casi inmediato y apoyos restaurativos ante las crisis.

La versión web 2.0 y la web federada con sus plataformas, destacan la pluralidad y minimizan la centralización. Su intención no es inducir al usuario hacia la búsqueda de información, haciéndole suponer que posee seguridad; sino que le obsequia la información para adquirir seguridad con las estrategias de prevención.

La utilidad de las redes cibernéticas es variada: Twitter es óptimo para movilización, los Blogs son prácticos para la actualización, Facebook permite la difusión y el crecimiento, la web federada propicia la colaboración, organización y protección.

Para establecer el cabal alcance de las TIC en la prevención comunitaria del delito cabe distinguir las versiones 1.0 a 3.0 de la web, pues la versión 1.0 presenta muchas similitudes con los medios masivos tradicionales de comunicación debido a su emisora unilateralidad. La figura 1 permite visualizar la evolución de la web.

Quizáparalaspersonasnofamiliarizadas técnicamente con Internet, lo anterior sea poco significativo. Pero el poder de Internet puede resaltarse con la práctica cotidiana de la "sindicación", que en términos comunicativos 
Figura 1: evolución de la web 1.0 a la web 3.0

\begin{tabular}{|c|c|c|}
\hline Web 1.0 & Web 2.0 & Web 3.0 \\
\hline $\begin{array}{l}\text { Personas conectándose a } \\
\text { la web }\end{array}$ & Personas conectándose a personas & $\begin{array}{l}\text { Aplicaciones web conectándose a } \\
\text { aplicaciones web }\end{array}$ \\
\hline $\begin{array}{l}\text { Conexión exclusiva de } \\
\text { emisor a receptor }\end{array}$ & $\begin{array}{l}\text { Conexión bidireccional entre } \\
\text { emisores y receptores }\end{array}$ & Conciencia de la web Geoespacial \\
\hline Doble click & Anuncios inteligentes & Autonomía respecto del navegador \\
\hline Sitio de fotos "Ofoto" & Sitio de fotos "Flickr" & Construcción de la web semántica \\
\hline Servicio "Akamai" & $\begin{array}{l}\text { Programas para archivos como } \\
\text { "BitTorrent" }\end{array}$ & $\begin{array}{l}\text { Genera experiencia y cultura } \\
\text { política entre personas }\end{array}$ \\
\hline $\begin{array}{l}\text { Sitio web de descarga de } \\
\text { música, videos, textos }\end{array}$ & $\begin{array}{l}\text { Programas par a par para compartir } \\
\text { música ("Napster"), propiedad } \\
\text { virtual ("Second Life") }\end{array}$ & Web tercera dimensión \\
\hline $\begin{array}{l}\text { Enciclopedia Británica en } \\
\text { línea }\end{array}$ & Proyecto Wikipedia & Genera nueva información \\
\hline Sitios personales & Bitácoras electrónicas & Aplicaciones y agentes de usuarios \\
\hline Screen scraping & Servicios en red & Servicios sobre la web misma \\
\hline Visualizaciones de página & Costo por click & \\
\hline Directorios (por taxonomía) & $\begin{array}{l}\text { Etiquetado (por taxonomía } \\
\text { popular, sin jerarquías ni } \\
\text { predeterminaciones) }\end{array}$ & $\begin{array}{l}\text { Inteligencia artificial para decisiones } \\
\text { por interés del usuario }\end{array}$ \\
\hline Publicación & Participación & $\begin{array}{l}\text { Compartir, procesar y transferir } \\
\text { ubicuamente información }\end{array}$ \\
\hline $\begin{array}{l}\text { Sistemas de manejo y } \\
\text { gestión de contenido ligados } \\
\text { a publicidad e ideologías }\end{array}$ & Enciclopedias colaborativas & Mapas temáticos automáticos \\
\hline Destacar un foro web & Redifusión en red & $\begin{array}{l}\text { Gestión de contenidos } \\
\text { seleccionados por interpretación }\end{array}$ \\
\hline Especulación con dominios & $\begin{array}{l}\text { Optimización en motores de } \\
\text { búsqueda SEO }\end{array}$ & $\begin{array}{l}\text { Captura y tratamiento inteligente } \\
\text { de datos }\end{array}$ \\
\hline
\end{tabular}

Fuente: elaboración propia a partir de O’Reilly (2005), Van Der Henst (2005) y Bravo (2007).

es el apoyo automático entre ciudadanos. Consiste en generar o seguir hipervínculos (la palabra o frase subrayada de distinto color que en la pantalla abre una nueva "ventana", o la aparición automática de "lo más visitado" en páginas electrónicas, o la creación de plataformas compartidas como answers.yahoo.com y www. slideshare.net). Con los hipervínculos se pueden encontrar, seguir, suscribir, organizar y enlistar palabas y asuntos del interés de la seguridad ciudadana. Los hipervínculos tienen la ventaja de compartir información vetada u ocultada en algún medio, pues esta se puede alojar en otro y darle acceso a través de enlaces alternos. 
Los hipervínculos se manejan paralelamente al establecimiento de tendencias, tanto para crearlas como para difundirlas de manera viral. Cullum (2010) creó una estrategia en ocho pasos para crear tendencias y lograr que los nodos de los hipervínculos no sean vetados $u$ ocultados, pues se pueden detener los mensajes, pero no a los medios mismos. La prueba histórica de que existen varios modos para burlar la censura que un régimen tiránico aplica a Internet radica en el logro de los twitteros en el año 2010 que consiguieron informar al prisionero Liu Xiaobo, aún custodiado bajo el estricto sistema penitenciario chino, que había obtenido el Premio Nobel de la Paz.

Además, cuantos más enlaces apunten hacia una página electrónica, más exitoso será el anidamiento en distintos medios y por diversos caminos. En el ámbito comercial es común hallarlos ofreciendolas calificaciones de pasajeros en líneas aéreas, huéspedes de hoteles y consumidores de diversos servicios. Los hipervínculos producen una sensación de credibilidad y transparencia en la información. Técnicamente, los nodos o intersecciones de la red electrónica, por ser infinitamente exponenciales en su propia programación y reconexión, pueden establecerse por diversas rutas de manera imparable. De ahí la metáfora biológica de la "acción viral" en Internet.

Manuel Castells (2009) ha insistido en ello de manera lúcida al especificar los anidamientos del poder en la web. Existe el poder de conectar en red, el poder en red y el poder para crear redes. El primero "consiste en la capacidad de dejar que un medio o un mensaje entre en la red mediante procedimientos de filtro de acceso" (p. 538). El poder en red, continúa el mismo autor, "es la forma del poder que ejercen determinados nodos sobre otros" (p. 538). Ante lo cual queda explícito que el poder de conectar en red puede generar $u$ omitir filtros de nodos o filtros de mensajes, y por ello puede afirmarse que el medio no es el mensaje. Pues el filtro de mensaje no filtra los nodos ni sus redes. El poder para crear redes, que puede originarse del poder de unos nodos sobre otros, según Castells (2009) "es la capacidad de configurar y programar una red" (p. 539). Este último poder desborda el control que los propietarios, directivos o gobierno tienen sobre los medios de comunicación en red porque se pueden detener los mensajes, pero no los medios mismos. En consecuencia, una vez en el ciberespacio, la ciudadanía puede desafiar el poder de los criminales, pues el poder para crear redes lleva a un nuevo poder: el poder de conexión. Este es, dentro de las definiciones de Castells (2009): "la capacidad para conectar dos o más redes diferentes mientras cada una sigue construyendo el poder en su ámbito respectivo" (p. 548). Poder de conexión entre ciudadanos y Estado, entre Policía y personas comunes, entre agencias de gobierno e instancias civiles: toda una red de gobernanza al servicio 
de la prevención delictiva. Como, por ejemplo, se ha instrumentado con grandes éxitos en Estados Unidos de Norteamérica a través de los portales web: http://www.crimereports.com; http://www.crimemapping.com; http:// www.spotcrime.com. O en Londres, por medio del portal: http://maps. met.police.uk/. También en grandes ciudades a través de los diarios locales $\mathrm{u}$ organizaciones civiles que establecen nexos con los Departamentos de Policía, como por ejemplo The New York Times: http://projects.nytimes.com/crime/ homicides/map o en Chicago: http:// bandittrackerchicago.com/

Las nuevas aplicaciones para Smartphones y Tablets, aunadas a las plataformas y redes ya mencionadas, terminarán por transformar el hábito de llamar por teléfono a la estación central de la Policía. También con el hábito policial de esperar la Ilamada de las víctimas o testigos situacionales, para redistribuir el mensaje al polígono afectado y de ahí a la unidad móvil (auto-radio-patrulla) de atención; procedimientosqueimplican untiempo valiosísimo en la reacción, aunque los autos-radio-patrullas estén a la vuelta de la esquina. La interconectividad del sistema, la aplicación cargada en los dispositivos de todos los ciudadanos y los policías en un mismo cuadrante, pueden evitar esa pérdida de tiempo y el sabotaje de hackers si se han programado correctamente en los planes de prevención la vigilancia comunitaria con video-cámaras y la georreferenciación satelital, tal y como lo ofrece en España la compañía Belt Ibérica, S.A. (www.belt.es), que proporciona, entre otros servicios, la grabación del delito o el accidente y también la posibilidad de grabar la ubicación y los datos de las diferentes ocurrencias sobre plano a partir de la dirección.

No obstante, en casos de solo avisos no emergentes, al ciudadano le agradaría recibir un acuse de recibo personalizado de la información que aportó, pues en una plataforma electrónica ello puede ser sustituido por el mensaje de un Bot o robot informático, lo cual acarrea baja credibilidad en la recepción informativa y dejaría de fomentar la proximidad y la gobernanza. El uso de las plataformas también acabará con los hábitos de buscar en fuentes difíciles e inciertas la información delictiva que el ciudadano y las autoridades policiales requieren para las estrategias de prevención. Datos que pueden obtenerse en informes escritos o gráficos a partir de la georreferenciación como lo permiten los portales web ya citados de Estados Unidos, Gran Bretaña y España.

En las características que la figura 1 presenta para la web 3.0 puede observarse que las aplicaciones web conectándose entre sí provocan la acción viral útil para certificar si la información procedente de la comunidad puede ser confiable. La conciencia de la web geo-espacial, la transferencia ubicua de información, la generación de nueva información, 
las aplicaciones y agentes de usuarios, la inteligencia artificial para decisiones por interés del usuario y sobre todo los mapas temáticos automáticos, permiten generar con facilidad tanto la georreferenciación del delito como la cartografía policial necesaria para los patrullajes y la intervención ciudadana.

Se han descrito las variables y las constantes del territorio a controlar por la prevención comunitaria del delito. Con ambos grupos de datos pueden realizarse los documentos de georreferenciación y las cartografías policiales. Los primeros deben incluir el levantamiento topográfico de cuadrantes o polígonos, la densidad poblacional de los mismos, la actividad económica y social preponderante, los niveles socioeconómicos principales y el tipo de zona predominante (escolar, comercial, industrial, habitacional, rural, etc.), con sus horarios regulares. La cartografía policial debe ubicar diferenciadamente los tipos de delitos, la estadística de horario y días de la semana, la recurrencia de las víctimas, las denuncias registradas y los modos de operar en cuanto a número de infractores, armas empleadas o tipo de violencia ejecutada.

Los casos de georreferenciación en Monterrey, México: Centro de Integración Ciudadana, Likter, y "El Bronco"

En el área urbana de Monterrey, Nuevo León, México, la delincuencia organizada tuvo una presencia devastadora durante la década de 2003 a 2013. Eso propició la movilización de la sociedad civil hacia la prevención delictiva, tanto en formas no organizadas como en movimientos institucionalmente organizados.

Los ciudadanos utilizaban sus redes sociales cibernéticas, sobre todo vía Facebook y Twitter, para darse aviso entre ellos mismos de incidentes delictivos o zonas de riesgo. También para transmitir información sobre rutas, destinos y horarios de patrullaje de la Policía federal, con el propósito de sumarse en caravana para obtener mayor seguridad en los trayectos largos por carreteras aisladas o sin control.

Paralelamente a las formas no organizadas, en el 2011 un grupo de ciudadanos se aliaron con algunas empresas y formaron el Centro de Integración Ciudadana (CIC). Esta institución opera principalmente a través de su portal web: www.cic.mx. Dicho centro posee varios programas, entre ellos destacan cuatro. Un programa de apoyo legal y otro de apoyo psicológico a víctimas del delito. Un servicio de enlace entre ciudadanos y algunas autoridades municipales, estatales y federales - particularmente el caso de la Comisión Federal de Electricidad-. Y también la estrategia denominada Tehuan (término que en lengua nahúatl significa "nosotros").

La estrategia Tehuan tiene como propósito recibir reportes de parte de 
los ciudadanos, registrarlos, validarlos, darles seguimiento, darlos a conocer en el web site y reenviarlos a los dispositivos móviles de los ciudadanos registrados en el programa. De esta manera se pretende dar información, lo más oportuna posible, que permita a las autoridades y a los ciudadanos tomar decisiones en un número muy amplio de aspectos, como se detalla más adelante. Inclusive, en el proyecto de la aplicación Likter se puede elegir cualquier territorialidad, independientemente de ubicación geográfica del usuario.

Tehuan inició utilizando la telefonía móvil con mensajes sms y el correo electrónico en comunicaciones bilaterales con sus afiliados. Para 2015 cuenta con Twitter, aplicaciones móviles para iOS y Android, Ilamadas telefónicas a número convencional o gratuito, mensajes sms, correo electrónico y la api: developers.cic. $\mathrm{mx}$. Sin embargo, para emitir alertas en tiempo real, hacia los dispositivos móviles de ciudadanos registrados, se redujo a las aplicaciones que pueden ser soportadas únicamente por Android y el sistema iOS. Los demás medios son útiles para validar reportes, pero no para la interactividad comunicativa bilateral.

La estrategia Tehuan aporta varios aprendizajes: en primer lugar es un ejercicio de gobernanza local. La información recibida es vertida en un reporte, este recibe un número de identificación y es turnado para su difusión y atención. En caso de que no sea validado o atendido, el ciudadano emisor puede establecer contacto para solicitar la resolución de su reporte.

En segundo lugar, como la plataforma tecnológica es de colaboración masiva, el tipo de reportes que pueden enviarse y recibirse es muy variado. En consecuencia, la misma plataforma establece la posibilidad de elección entre las siguientes categorizaciones: a) comunidad, que contiene avisos, información de eventos públicos, reportes de observador ciudadano sobre anomalías y el reconocimiento a acciones cívicas a través de la sección Mtymuybien (sic); b) propuestas ciudadanas, donde caben diseñar alternativas para problemas del orden de la comunidad, seguridad, servicio y vialidad; c) seguridad, que contiene los rubros de incendio, robo, robo de auto y situación de riesgo, en esta última se pueden reportar todo tipo de incidentes o presuntos delitos. Por tanto, es la más significativa en términos de prevención georreferencial; d) servicios públicos, donde pueden reportarse irregularidades de alcantarillas, alumbrado público, falta de electricidad, fugas de agua o gas, parques descuidados, falta de recolección de basura; e) vialidad y tránsito, en lo que corresponde a accidentes automovilísticos, baches o vía dañada, obras y/o vía cerrada, semáforos descompuestos, y f) emergencias médicas.

La plataforma ofrece, en lo concerniente al rubro de seguridad, la amplia categoría de situación de riesgo. 
La ciudadanía reporta robos a casa de habitación, robo de automóviles, robo a transeúntes, actividades de pandillas, balaceras, homicidios, hallazgos de cadáveres y todo tipo de actividades sospechosas que pudieran derivar en acciones delictivas. La plataforma cuenta con una sección de open data; en esta pueden consultarse 20 tipos de reportes, aunque no todos son elaborados por el Centro de Integración Ciudadana, pues algunos proceden de la Procuraduría General de Justicia de la Nación o del Instituto Nacional de Estadística y Geografía.

En tercer lugar, respecto a la georreferenciación del delito, para la zona metropolitana de Monterrey cabe destacar el reporte de seguridad emitido hacia su plataforma por la ciudadanía. La información se organiza por categoría, título de reporte, ubicación en latitud y longitud, descripción, número de reporte, estado de reporte, fecha y hora de creación del reporte. Además, dicho reporte puede consultarse con vista de mapa (puede consultarse en: https:// data.cic. $\mathrm{mx} /$ Seguridad/VialidadSeguridad-y-Mapa-del-Delito-enVista-de-M/95jt-qbxf).

La síntesis de esa información es casi una cartografía policial pública, que puede ser aprovechada por las organizaciones policiales y también por la ciudadanía.

Por tanto, los servicios de la estrategia Tehuan pueden visualizarse bajo dos perspectivas en la prevención del delito. Cuando el servicio ofrece información en tiempo real, vía los dispositivos móviles habilitados, a los ciudadanos registrados, entonces se convierte en un elemento de la prevención situacional del delito, pues los ciudadanos quedan advertidos en qué momento y lugar ocurre un asalto,

Figura 2: Mapa del delito de la plataforma del Centro de Integración Ciudadana

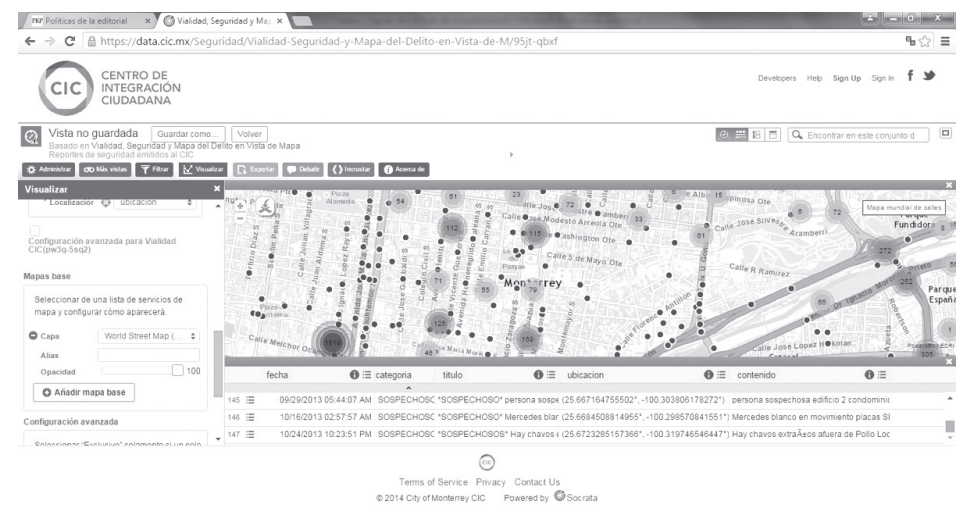

Fuente: Centro de Integración Ciudadana (2015). 
una balacera, una riña entre pandillas, un grupo de personas drogándose en la vía pública, etcétera, o cualquier situación considerada de "riesgo". Para las autoridades policiales es útil como validación que le permite la asignación de recursos humanos y materiales en las operaciones de reacción. La otra perspectiva corresponde a la cartografía policial, pues la información que aporta puede utilizarse en el sentido de contar con los datos básicos para establecer los programas de trabajo en la prevención comunitaria del delito.

Otra de las acciones realizadas en el área metropolitana de Monterrey es el proyecto Likter que todavía está en construcción. Likter nació de una iniciativa completamente ciudadana, con el deseo de otorgar expeditamente a la ciudadanía, por los ciudadanos mismos, un cúmulo de información concreta y práctica que por otros medios no obtendría. En consecuencia, también proporciona a las autoridades policiales la información en tiempo real de eventos delictivos. Así, soterradamente, al permitir a los usuarios que se convirtieran en reporteros, la ciudadanía y la Policía tendrían a su disposición la información sobre hechos delictivos. El proyecto inicia como un acontecer noticioso de información general y de muy variada índole, para derivar en un instrumento contra el delito. No obstante, para efectos de georreferenciación del delito, el proyecto Likter debería reducir sus múltiples categorías a la de Seguridad Pública, o al menos destacarla privilegiadamente, pues esa es la razón de su génesis originaria. En ese sentido, es una aplicación completamente enfocada a constituir una base de datos que indica lugar, momento y descripción de acontecimientos.

La aplicación Likter puede consultarse en los videos promocionales que se encuentran anidados en la red social de YouTube. Una de las descripciones más amplias se hallan en el "Tour de Likter" (versión español) (https://www.youtube.com/ watch? $v=A B v W q q q h C 4 g)$.

Likter permite generar y consultar noticias en la red social en tres categorías: en vivo, del orden popular y confiables. Los usuarios tienen la capacidad de validar o invalidar la veracidad de una noticia, y la verificación se pondera con mayor peso según la cercanía del usuario al lugar de los hechos referidos, de modo que un usuario tendrá más poder verificativo entre mayor valor presencial posea. La validación de la información que permite la aplicación Likter representa un criterio deseable para asignar recursos humanos y materiales de parte de los cuerpos policiales a los casos de intervención y para considerar la georreferenciación al diseñar los programas de prevención comunitaria.

La aplicación permite crear una noticia que, de manera automática, se ubica en un mapa convencional (cualidad 
Figura 3: Muestra de la aplicación Likter

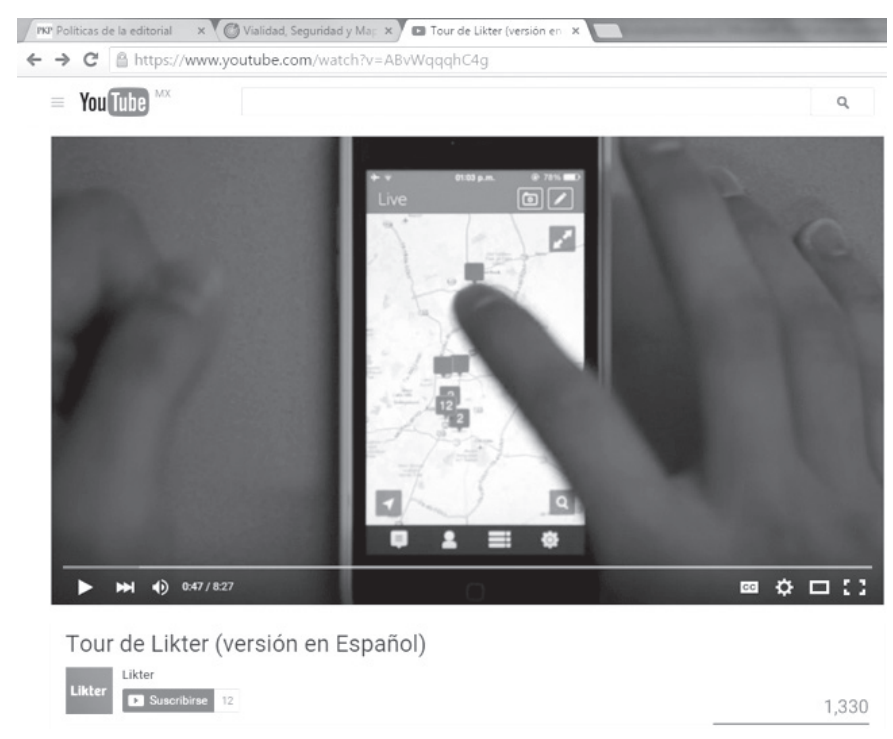

Fuente: Likter (2015, noviembre, 24) Tour de Likter (versión en español). [Archivo de video]. Recuperado de: https://www.youtube.com/ watch? $v=$ ABvWqqqhC4g

superior a la característica del programa Tehuan, pues este da las coordenadas geográficas $y$, por lo general la ciudadanía y los cuerpos policiales no usan la nomenclatura geográfica de latitud y longitud, sino la de los mapas convencionales), permite hacer una descripción del evento y también subir fotos. El archivo de Likter opera por cuadrantes, que pueden extenderse o restringirse discrecionalmente $y$ otorga automáticamente las últimas veinte noticias de dicha área. También se pueden consultar datos de mayor antigüedad. El usuario puede proceder de manera más práctica al seleccionar su perfil y el área geográfica o ciudad de adscripción.
Al proyecto Likter le falta una sistematización organizada de la información y una sub-clasificación dentro de la categoría Seguridad Pública. Por ello, en su actual fase de desarrollo, presenta más utilidad para la reacción de la fuerza pública que para la prevención, dado que esa era la idea original. Si Likter completara su estructura de manera orgánica y con miras al establecimiento de la cartografía policial, tendría un altísimo potencial para la prevención comunitaria del delito y, en perpetuo tiempo real, permitiría a la ciudadanía tomar el control de su territorio. 
Por otra parte, respecto a un área colindante con la metrópoli de Monterrey, el 25 de agosto de 2015 el gobernador electo del Estado de Nuevo León, Jaime Rodríguez Calderón (conocido como "El Bronco"), haciendo referencia a dicha zona, durante su gestión como presidente del municipio de García, declaró en una entrevista periodística: "Yo vencí a Los Zetas utilizando Facebook. En mi ciudad, preguntándole a la gente quién vende droga, quién está haciendo daño en la colonia, la gente te dice: entonces tú, como autoridad, tienes el control y resuelves" (Vencí a Los Zetas en Facebook, 2015).

La declaración merece varias observaciones. En primer lugar, la declaración debe contextualizarse: "Los Zetas" son una organización criminal que se independizó -toda vez que fue la sección armada-, de otra de las organizaciones criminales de alto impacto en México. En segundo lugar, ese grupo delincuencial no operó exclusivamente en el municipio de García, de manera que, aunque el grupo se haya desplazado del municipio de García, la declaración debe tomarse como una victoria inicial. En tercer lugar, el aspecto de interés para este texto es que la declaración hace referencia a la aplicación transversal de las TIC en la solución y prevención del delito. Es decir, una experiencia de comunicación y acción entre autoridades y ciudadanía y, sobre todo, de la preferencia de las TIC.
En la actualidad no es posible consultar el Facebook del entonces presidente municipal de García para hacer un análisis del alcance de su declaración. Sin duda, la tesis se sostiene: dicha red social cibernética resultó fuente de información para la georreferenciación cartográfica del delito, su persecución y su posible prevención. La idea, no obstante, no presenta un modelo de gobernanza, sino de cooperación comunitaria con las autoridades. Alcanzar la cualidad de gobernanza implicaría elevar la información ciudadana y la acción policial a programas de prevención comunitaria, siempre basados en evidencia validada y proyectados con metodologías sociales comprobadas. Pero este testimonio aporta una enseñanza importante: si la ciudadanía confía en las autoridades responsables de la seguridad pública, entonces la participación contra el delito (en este caso, semipreventivo, pues nace de una denuncia no formal, es decir, emergente y casi a priori del delito) poseerá la base para realizar acciones preventivas organizadas.

La georreferenciación ofrece ventajas contra el delito, tanto reactiva como preventivamente. Por ejemplo, el conocimiento de la geografía física del territorio a controlar aporta una ventaja espacial (cuestas o brechas de difícil tránsito, tanto para evitar los escapes de los infractores o la vulnerabilidad de los patrullajes; escondites o sitios para evitar o realizar emboscadas; puntos privilegiados de visión directa o con equipos 
técnicos, etcétera). La cartografía digital, con las posibilidades tecnológicas de establecer una suma-toria histórica en el mapa delictivo y los equipos de geoposicionamiento, permite validar una alta probabilidad de certeza estadística ante un aviso de emergencia. De esta manera las TIC y los software especializados para el análisis de la información y la priorización en la toma de decisiones, apoyan la implementación de programas ciudadanos de prevención comunitaria.

Se han citado ya los niveles estructurales de la prevención delic-tiva. Dentro de estoscabe referenciaralgunos programas de prevención comunitaria, como las escuelas de seguridad ciudadana, los frentes locales de seguridad, los líderes e inspectores en comisarías de barrio, los centros o comisiones de mediación y resolución de conflictos, los planes de trabajo comunitarios, de reinserción social, las campañas de desarme, los talleres contra la deserción escolar, el vagabundeo, el alcoholismo, las drogas, y un larguísimo etcétera. Y si bien es muy importante implementarlos con procesos de desarrollo en autogestión y sustentabilidad, también es imprescindible saber dónde ubicarlos, por cuánto tiempo según sus objetivos y con qué instrumentaciones adecuadas al entorno comunitario.

\section{Conclusión}

Una de las dificultades prácticas que el Estado enfrenta es la falta oportuna de toda la información real, puesto que no todos los ciudadanos acuden a levantar las denuncias contra el delito del que han sido víctimas. El Estado, en estricto censo, solo se puede guiar por las denuncias, dado que tiene que proceder conforme a Derecho. Los avisos o alertas y las denuncias sirven para la reacción, y han de servir para la prevención.

Junto con lo anterior, una dificultad de índole técnica es grave para sostener la georreferenciación en perpetuo tiempo real: la sustentación de los servidores u ordenadores físicos donde se almacena la información y los sistemas para acceder a dichos servidores u ordenadores. Estos servidores deben tener la capacidad de permanecer operativos sin interrupción, realizar respaldos automáticos alrededor de cada seis horas (dependiendo de cuánta información circula por ellos), y no contener sistemas operativos con desfasamiento de actualizaciones, pues esto último impide el acceso remoto o físico a la información. De no solventar esta dificultad técnica, el patrullaje no resultará suficientemente oportuno en la reacción.

Aunque el patrullaje es la actividad de percepción más confiable para la ciudadanía, no se trata de establecer la georreferenciación para diseñar estrategias solo reactivas. La evolución hacia la gobernanza en Seguridad Pública trata de aprovechar las TIC para establecer la georreferenciación en un gobierno abierto y con programas 
de participación ciudadana. En otras palabras, la Policía, por su parte, puede ejecutar tanto actividades de reacción como de patrullaje para lograr la prevención situacional, y la ciudadanía, por la suya, implementar la prevención comunitaria. Ambas instancias tendrán más éxito si lo hacen colaborativamente.

La complejidad de los problemas y las dimensiones de la información requieren el apoyo de las nuevas tecnologías, no solo de la información y la comunicación, sino también de los software para la toma de decisiones, la ejecución de mandos y operativos y la planeación de programas preventivos. Ello implica un ejercicio de gobernanza donde la participación ciudadana ha de estar involucrada. Sin embargo, desde la información básica inicial, los tres casos aludidos, sobre todo para la comunicación bilateral en tiempo real, presentan las dificultades de la brecha digital. En particular, para Tehuan y Likter, solo los usuarios que puedan soportar aplicaciones móviles para iOS y Android tienen la oportunidad de participar reactiva o preventivamente para romper la cadena delictiva o de la victimización.

Otro aspecto, no menos importante, es la falta de garantías para la resolución de las problemáticas emergentes, sobre todo en lo concerniente a la reacción ante el delito. El presupuesto gubernamental es limitado y, por tanto, los recursos humanos y materiales pueden no ser suficientes para atender las advertencias ciudadanas. La situación se agrava en especial para todos los casos presentes en el Centro de Integración Ciudadana, porque este trata con un número muy amplio de variables. En el caso del interés de este texto, respecto a la Seguridad Pública, como es bien sabido, también en términos presupuestales es mejor prevenir el delito que castigarlo $y$, aun así, la prevención comunitaria no garantiza la resolución de todas las problemáticas emergentes.

Para el programa Tehuan del $\mathrm{CIC}$ un área de oportunidad se encuentra en actualizar la información y llegar a operar las advertencias en tiempo real. Por otra parte, tanto el programa Tehuan como el proyecto Likter y la estrategia del gobernador Jaime Rodríguez ("El Bronco") se enfrentan a la dificultad de validar la información. En este sentido, la colaboración ciudadana, en la medida de su amplitud y congruencia, es útil para la confirmación y el diseño de la cartografía policial. Aunado a lo anterior, de acuerdo con la Estrategia Digital Nacional, los avisos y alertas no se presentan como un instrumento jurídicamente formal de denuncia. Sería altamente recomendable establecer la vinculación con el gobierno electrónico a través de la instrumentación correspondiente de la web federada para tales efectos.

De lo anterior se desprende que, si bien es muy valiosa la aportación georreferencial que proporcionan las TIC, debe tomarse en cuenta que 
dicho apoyo no se trata simplemente de poner más puntos rojos o amarillos en un mapa digital. Tampoco de identificar la concentración estadística de puntos o de aumentar el número de servidores de seguridad pública en función del incremento estadístico. Sino, como atinadamente ha dicho un experto, "se trata de construir teorías sobre el funcionamiento de las organizaciones criminales [...y a su vez] identificar las debilidades del Estado" (De León, 2012), es decir, se trata de conocer los pormenores del crimen para romper la cadena del delito. Y para lograr dicha ruptura y superar las debilidades del Estado, la gobernanza apunta a la acción colaborativa entre Estado y participación ciudadana.

\section{Estas discusiones conclusivas} responden a la pregunta inicial sobre las fortalezas y áreas de oportunidad para Nuevo León e ilustran la problemática para otras regiones. No obstante, a la cuestión corolaria: ¿Fuerza Civil (la Policía estatal de Nuevo León) debe ampliar su margen de acción hacia la prevención con apoyo de las redes sociales cibernéticas y las plataformas electrónicas en franca integración con la gobernanza?, cabe responder con un franco sí y explicar por qué una Policía altamente capacitada para hacer uso escalonado ascendente de la fuerza también debe atender asuntos de proximidad y prevención comunitaria. En primer lugar, bajo el principio lógico de "quién puede lo más también puede lo menos" se llegará a la conclusión de que una Policía de orden estatal también puede realizar tareas de Policía de proximidad si se capacita para ambas cosas. Por tanto, llevar a cabo tareas de prevención comunitaria con el apoyo de las TIC. Palacios (2013) indica que:

[...] al tener mayor conocimiento
de sus cuadrantes, en cuanto
a espacio físico, personas y
criminales recurrentes, el informe
policial homologado que realice
[refiriéndose a la Policía de
proximidad o municipal] será de
gran utilidad para que las Policías
de niveles 2 y 3 [es decir, Policías
estatales y federales] operen el ciclo
de inteligencia. En otros términos
[indica este autor], la Policía de
proximidad es un engrane que
mueve a los demás (pp. 80, 81).

Por tanto, es altamente deseable una reciprocidad colaborativa entre la Policía de proximidad y las Policías estatales, como lo es Fuerza Civil y, consecuentemente, Fuerza Civil habría de cooperar en la modalidad de prevención para tomar el control del territorio. Control que debe entenderse de tipo comunitario.

En segundo lugar, Palacios (2013) también indica que: "desde un punto de vista progresivo, la visión sería que las Policías, niveles 2 y 3 , 'incubaran' a la de proximidad" (p. 88). Aunque esto pueda provocar interpretaciones disímiles, es posible comprender que las Policías estatales tienen la capacidad de recibir los beneficios de la información, 
comunicación e interacción propios de la escala municipal, que resulta el primer peldaño de la gobernanza. Particularmente para elaborar las cartografías policiales.

En tercer lugar, debe evitarse el equívoco superficial. Que las Policías de mayores rangos (nacionales o estatales) puedan realizar tareas de Policías de menor rango (municipales o de proximidad) no significa directamente que cambien de una profesionalización de Policías reactivas a Policías preventivas. Pero la cuestión no superficial, sino profunda, es la adaptabilidad hacia la prevención. Es decir, la tesis derivada del principio general sostiene: "la corporación que puede prevenir lo más, también puede prevenir lo menos". Y la conclusión es: se puede recuperary sostener el control de un territorio al prevenir la escala de lo mayor (delitos de alto impacto) y ampliarla a lo menor (entiéndase hacia delitos de menor impacto para evitar un oxímoron). Siempre y cuando la capacitación policial no excluya los aspectos proactivos al privilegiar los meramente reactivos.

En Latinoamérica existen varias pruebas empíricas de cómo una Policía de nivel 3 o nacional también puede trabajar en el nivel 1 o municipal-comunitario. Por ejemplo, la Policía Nacional colombiana, a partir de 2006, aplicó el programa de Vigilancia Comunitaria "Vicom-2006" constituyendo el antecedente del consolidado Plan Nacional de Vigilancia Comunitaria por
Cuadrantes establecido desde 2010. En su respectiva dogmática policial, expresada en la Estrategia de la Policía Nacional para la Consolidación de la Seguridad Ciudadana, incluye dos de los elementos que consolidan las acciones de gobernanza: el "Sistema de Participación Ciudadana" (Policía Nacional de Colombia, 2010, pp. 115-120) y algunos aspectos de "Las TIC para la seguridad ciudadana" (Policía Nacional de Colombia, 2010, pp. 139-147). Es destacable del caso colombiano el hecho de que los elementos policiales signados a cuadrantes otorgan -como parte del programa institucional- los números telefónicos y datos de vinculación de sus aparatos móviles. Ello con el propósito de establecer un contacto inmediato sin necesidad de triangular la emergencia a una central.

Otro caso empírico que demuestra la viabilidad de una Policía de nivel nacional, inclusive con formación militar, trabajando en la escala comunitaria y preventiva, es la Policía de Carabineros de Chile. En ese país del cono sur americano se estableció, desde el 2006, la Estrategia Nacional de Seguridad Pública, que contempló líneas de operación en prevención social y prevención situacional (Gobierno de Chile, 2006) y que ha evolucionado hacia diversos planes y programas con los cambios de administración y definición de políticas públicas actualizadas. En la versión 2014 (Plan Nacional de Seguridad Pública y Prevención de la Violencia 
y el Delito, Seguridad para Todos) si bien contempla la georreferenciación delictual y preventiva realizada en gobernanza, todavía no incluye los aportes de las TIC.

Una prueba empírica más la constituye la Policía Nacional Civil de El Salvador, a través de su División de Policía Comunitaria que, entre otras actividades características de la gobernanza en la prevención del delito, cuenta con las Patrullas de Intervención Policial Comunitarias (PIP-COM) y los Foros de Consulta Ciudadana, además de los Comités de Seguridad Ciudadana. Los dos últimos con una significativa función de recolectar la información para la planificación de acciones policiales, de carácter preventivo y operativo (Gobierno de El Salvador, 2015). Y paralelamente a dichas instancias institucionales, la Policía Nacional posee cuentas de Facebook y Twitter habilitadas donde los ciudadanos pueden seguir la información puntual proporcionada por la Policía Nacional y, a su vez, exponer sus necesidades y la valiosa información para operaciones reactivas o planes preventivos.

En lo concerniente a que Fuerza Civil en Nuevo León, México, pudiese adaptarse a labores de prevención comunitaria, cabe destacar que su dogmática policial posee suficiente solidez para permitirle a dicha corporación de nivel estatal el tránsito desde la reacción policial hasta la prevención y la proximidad. En los valores característicos expresados en la dogmática policial de Fuerza Civil destacan la amabilidad, el buen trato y la unión con la ciudadanía. La primera es definida como:

\begin{abstract}
Respetar al próximo por igual, con mayores consideraciones a los grupos vulnerables: niños, ancianos, personas con capacidades diferentes, etc. [De donde se sigue el buen trato a los habitantes en el tenor de que] Tanto el policía como la comunidad deben comprender que el policía es parte de la comunidad y que la comunidad forma parte de su Policía [...] Comunidad y policía son una misma cosa (Palacios, 2014b, p. 28).
\end{abstract}

Asimismo, la unión con la ciudadanía contempla: "ganarse la confianza de la gente por su buen trato [...] Incluso, cuando el policía establece un canal de comunicación con base en la confianza, la ciudadanía le proporciona la información necesaria para que él haga un mejor trabajo preventivo" (Palacios, 2014b, pp. 28-29).

Sindudaalguna, laciudadanía de Nuevo León preferirá poseer programas de prevención comunitaria en los cuales Fuerza Civil se encuentre profunda y constantemente involucrada en vez de verse en la necesidad de hacer la típica "llamada telefónica a la Policía" para atender un evento a posteriori.

Finalmente, pero no por ello menos importante, en la actual era digital será preferible una interconexión 
directa entre ciudadano y agente policial a través de la web federada; tanto para evitar la llamada telefónica de reacción, como para establecer la información básica de la cartografía policial, de donde se desprenderán los programas para recuperar o sostener el control del territorio.

\section{REFERENCIAS}

Aguilar, L. (2007). El aporte de la Política Pública y de la Nueva Gestión Pública a la gobernanza. Revista del CLAD Reforma y Democracia, 39, Recuperado de: http://www.clad. org/portal/publicaciones-del-clad/ revista-cladreformademocracia/ a r t i c u l o s / 030 octubre-2007/0057201.

Aguirre, J. (2015). The model of participatory democracy powered by new media. Archiv für Rechtsund Socialphilosophie, 101, 442457.

Bravo, H. (2007). La web 3.0, añade significado. Recuperado de: http://www. maestrosdelweb. com/editorial/la-web-30-anadesignificado/

Castells, M. (2009). Comunicación y poder. Madrid, España: Alianza Editorial.

Centro de Integración Ciudadana. (2015) Mapa del delito. Recuperado de: https://data.cic.mx/Seguridad/ Vialidad-Seguridad-y-Mapa-delDelito-en-Vista-de-M/95jt-qbxf
Cerrillo, A. (2005). La gobernanza hoy: introducción. En: Agustí Cerrillo (comp.), La gobernanza hoy: 10 textos de referencia (pp. 11-36). Madrid, España: Instituto Nacional de Administración Pública.

Cullum, B. (2010). How to use hashtags on Twitter to spread, share and organize information. Recuperado de: http://www.movements.org/ how-to/entry/use-hashtags-ontwitter-to-spread-information

Dammert, L. (2005). Prevención comunitaria del delito en América Latina: desafíos y oportunidades. Desafíos, 13, 124-156.

De León, I. (2012). Georreferenciación del crimen en contextos de alta violencia. Colombia: Oficina de las Naciones Unidad contra la Droga y el Delito. Recuperado de: http:// www.inegi.org.mx/eventos/2011/ unodc_evento/doc/Isaac\%20Leon. pdf

Gobierno de Chile. (2006). Estrategia Nacional de Seguridad Pública. Súmate por un Chile +seguro. Recuperado de: https://www.oas. org/dsp/documentos/politicas publicas/chile.pdf

Gobierno de El Salvador. (2015). Policía Nacional Civil /Policía Comunitaria. Recuperado de: http://www. pnc.gob.sv/portal/page/portal/ informativo/temas/programas/ policia_comunitaria

Gobierno de la República. (2013). Estrategia Digital Nacional, México. 
Recuperado el 21 de octubre de 2015 de: http://cdn.mexicodigital. gob.mx/EstrategiaDigital.pdf.

Hernando, F. (2008). La seguridad en las ciudades: el nuevo enfoque de la geoprevención. Scripta Nova. Revista Electrónica de Geografía y Ciencias Sociales, XII, 270 (14). Recuperado de: http://www.ub.es/ geocrit/sn/sn-270/sn-270-14.htm

Kooiman, J. (2005). Gobernar en gobernanza. En: Agustí Cerrillo (comp.), La gobernanza hoy: 10 textos de referencia (pp. 11-36). Madrid: Instituto Nacional de Administración Pública.

Likter. (2015, noviembre 24). Tour de Likter (versión en español). [Archivo de video]. Recuperado de: https://www.youtube.com/ watch?v=ABvWqqqhC4g

Núñez, L. (2011). La prevención del delito a través de los paradigmas criminológicos. En: D. Ordaz, D. y Cunjama, E., (coord.), Criminología reflexiva, discusiones acerca de la criminalidad (pp. 49-76). Ciudad de México, México: Editorial Ubijus.

O'Reilly, T. (2005). What Is Web 2.0 Design Patterns and Business Models for the Next Generation of Software. Recuperado de: http:// oreilly.com/web2/archive/what-isweb-20.html

Osborne, D. and Gaebler, T. (1992). Reinventing Government. Massachutes: Addison-Wesley.
Palacios, G. (2013). Organización policial. Una propuesta para Nuevo León. Criminología y Sociedad, 2 y 3, 73-91.

(2014a). Criminología contemporánea. Introducción a sus fundamentos teóricos. Ciudad de México, México: Instituto Nacional de Ciencias Penales.

(2014b). Dogmática policial. Santa Catarina, México: Universidad de Ciencias de la Seguridad del Estado de Nuevo León.

Paniagua, A., Borunda, J. y Camargo, I. (2012). Transparencia, participación ciudadana y gobierno electrónico: el caso del Gobierno Local de Ciudad Juárez, México. Sociedade e Cultura, (15) 1, 99107.

Pavarini, M. (1994). Bisogni di Sicurezza e Questione Criminale. Rassegna Italiana de Criminología, V (4), 435-462.

Peters, G. y Jon P. (2005). ¿Gobernanza sin gobierno? Replanteándose la administración pública. En: Agustí Cerrillo (comp.), La gobernanza hoy: 10 textos de referencia (pp. 123-144). Madrid: Instituto Nacional de Administración Pública.

Policía Nacional de Colombia. (2010). Estrategia de la Policía Nacional para la consolidación de la Seguridad Ciudadana. Bogotá, Colombia: Publicación de la Policía Nacional 
de Colombia, Dirección General Oficina de Planeación.

Prats, J. (2005). Modos de gobernación de las sociedades globales. En: Agustí Cerrillo (comp.). La gobernanza hoy: 10 textos de referencia (pp. 145-172). Madrid: Instituto Nacional de Administración Pública.

Sozzo, M. (2000). Seguridad urbana y tácticas de prevención del delito. Cuadernos de Doctrina y Jurisprudencia Penal, VI (10-B), 17-82.

Van Der Henst, C. (2005). ¿Qué es la web 2.0? Recuperado de: http://www.maestrosdelweb.com/ editorial/web2/

Van Dijk, J. (1990). Crime Prevention Policy: Current State and Prospects. En: Kaiser, G. y Albrecht, HJ (ed.) Crime and criminal policy in Europe, Criminological research report, Vol. 43 (pp. 205-220). Freiburg, Germany: Max Planck Institute.

Vencí a Los Zetas en Facebook. (2015, agosto 25). Excelsior. Recuperado de: http://www.excelsior.com.mx/ nacional/2015/08/25/1041989 